\title{
Optimum Interaction between Soil Water Regime and Soil Warming for Convenient Plant Growth Conditions
}

\section{E. M. Hokam and I. H. El-Sheikh*}

Soil and Water Dept. and *Agricultural Engineering Dept., Fac. of Agriculture, Suez-Canal Univ.

\begin{abstract}
A BSOLUTE increase in soil moisture and warming should not A be considered as optimum environmental conditions for plant growth. Detection of optimum interaction between soil heat and moisture regime as successful practice for plant growth was the main objective of the present study. A field experiment was conducted in three unheated plastic greenhouses, in which black plastic sheet was used parallel to bare soil. Cucumber (Cucumis sativvs) was cultivated and irrigated with micro drip system to achieve three different moisture regimes: greenhouse no. 1 was always brought back to full soil field capacity, FC, while greenhouses no. 2 and 3 were brought back to two thirds and one third of soil FC, respectively. Sensors of digital thermocouple were used to measure soil temperature inserted in: 10, 20 and $30 \mathrm{~cm}$ soil depth associated with soil moisture contents. Statistical analysis indicated that, crop yield and some growth parameters were significantly affected by the different irrigation treatments. This finding was considered as basis for decision-making to detect the most appropriate interaction between irrigation and soil warming. The results showed that, the highest moisture contents were recorded at $20 \mathrm{~cm}$ depth under mulched soils compared to the upper and lower depths. Also, the lowest values of moisture fluctuation were found under all mulched soils compared to the bare, and were inversely related to both crop yield and growth parameters. High soil temperature (in the upper $20 \mathrm{~cm}$ soil layer) interacted with high moisture content was also proportional to crop yield, root depth and plant height in similar manner found with soil moisture fluctuation. Soil heat flux was increased under mulched soil and compared to heat storage, it can be a good indicator for soil warming, and temperature fluctuation, so, it somewhat agreed with moisture fluctuations. Based on observed moisture and soil temperature at different depths of bare soil treatments, it was expected that HYDRUISD-ID code could be used to predict the diurnal pattern of soil water dynamic. Regarding to suitable soil temperature for root growth, results showed that, optimum values were recorded in the uppermost 20 $\mathrm{cm}$ of mulched soil under greenhouses no. 1, 3 and associated with suitable plant growth.
\end{abstract}

Keywords: Soil moisture fluctuation, Irrigation regime, Temperature fluctuation.

Changing in soil temperature has been associated to changes in soil properties, such as, moisture content, $\mathrm{pH}$ and ion concentrations that in turn may affect soil respiration, microbial decomposition and mineralization, nutrients uptake and 
turnover of soil organic carbon (Campbell et al., 1994; Arin \& Ankara, 2001; Fan \& Liu, 2003 and Zhang et al., 2005). Soil surface temperature determines the flux of outgoing long wave, sensible and ground heat, consequently, determines the latent heat flux (i.e., evapotranspiration). So changing in surface temperature affects soil moisture and vice versa. Soil-water state generally differs from layer to layer at any given time. Therefore, Changes of soil temperature, along with concomitant changes in soil moisture, will lead to a wide range of soil and plant responses. Cleared and tilled soils which became warmer, accelerate rate of organic matter decomposition, enhance emitting $\mathrm{CO}_{2}$ from soil and exacerbate the greenhouse effect itself. Moreover, higher soil temperatures should generally accelerate chemical reaction rates and gaseous components are also affected (Buol, et al., 1990; Hillel et al., 1998 and Sanders, 2001). The absolute increasing in soil moisture or warming could not be considered as an optimum environmental conditions for plant growth, therefore, detecting the positively interaction between soil heat and moisture content to avoid high fluctuation of those properties was the aim of this investigation. Generally, soil temperature varies greatly with depth and overtime. In the upper soil layers, temperature fluctuates substantially in response to air temperature changes and radiant heat transfer, whereas, it is more stable in the deeper layers. Soil temperature has a substantially influence on plant root growth, where low soil temperature reduces both root elongation and respiration (Pahlavanian \& Silk, 1988 and Seyfi \& Rashidi, 2007). According to Gregory (2006), the minimum and optimum range of soil temperature (depend on plant species) are typically $0-12$ and $25-$ $35 \mathrm{C}^{\mathrm{o}}$, respectively. Early some investigators reported that, air temperature controls reproductive growth, while vegetative growth is controlled by root temperature. In other words, favorable soil temperatures may make it possible to produce two or more crops per year or achieve earlier crop maturity which may have marketing advantages (Barlow et al., 1974 and Boersma, 1972).

Water vapor transport can result in accumulation of liquid water in the unsaturated zone; in addition, it plays a very important role in maintaining vegetative and ecosystems in arid and semi-arid regions (Scanlon and Milly, 1994). Salzmann et al. (2000) reported that, coupled flow of energy and mass is greatly affected by the microscopic structure of porous medium. Zeng (2013) found that, the modified HYDRUSID-ID code provided a diurnal movement of liquid water, water vapor, so, simulated soil water flux, driven by both pressure head and temperature gradient under subsurface zone. He found that simulated soil temperature and water content were in good agreement with measured values.

Many previous investigations showed that plastic film created favorable conditions for increasing temperature in soil and its moisture content compared to bare soil (Richard, 1976; Wien \& Minotti, 1987; Salman et al., 1992; FariasLarios et al., 1994; Weber, 2000; El-Nemr, 2006 and Yang et al., 2013). They concluded that, use of plastic mulch (in general and regardless of, is it black or transparent?) would affect soil temperature in three main ways: reducing connective heat loss, outgoing radiation and evaporation, thus increasing soil Egypt. J. Soil. Sci. 56, No. 2 (2016) 
temperature. Black polyethylene mulch (as used in this study) exchanged large quantities of energy and caused relatively small changes in soil temperature, while transparent polyethylene film transmitted radiation to soil surface which absorbed and converted to sensible heat (Hopen, 1964; Haddadine, 1982 and El-Nemr, 2006). In fact, speed storage of heat during the daylight will lead to great cooling during the night-time, consequently, fluctuation of soil temperature. Moisture content kept in soil at any time (considered as a function of irrigation management and other soil properties) is directly involved with soil temperature. Hassanain and Hokam (2005) found that soil and air temperatures were strongly affected by different soil moisture contents. However, soil temperature only is not enough to describe the fate of energy into the soil as affected by its moisture content and its bulk density. The quantity of heat flows across a limited area of soil in limited time is a function of soil specific heat, bulk density, moisture content and the change in soil temperature, and it could be described and calculated according to Hanks and Ashcroft (1980) as following:

$$
\mathrm{Q}_{\mathrm{q}}=\rho_{\mathrm{b}}\left(0.2+\theta_{\mathrm{m}}\right) \mathrm{V}\left(\mathrm{T}_{1}-\mathrm{T}_{2}\right)
$$

where $\mathrm{Q}_{\mathrm{q}}$ is the quantity of heat (in cal.) flows in a defined volume, $\mathrm{V}$, of soil (across a unit area of soil section, $1 \mathrm{~cm}^{2}$ along $10 \mathrm{~cm}$ soil depth). $\mathrm{C}_{\mathrm{v}}$ is the volumetric heat capacity of soil, and calculated by $\rho_{\mathrm{b}}\left(0.2+\theta_{\mathrm{m}}\right)$, in which $\rho_{\mathrm{b}}$ is soil bulk density. For studied soil, 0.2 was assumed value of specific heat as average for mineral soils, in cal. $\mathrm{g}^{-1} \mathrm{C}^{\mathrm{o}-1} \cdot \mathrm{T}_{1}-\mathrm{T}_{2}$, is the difference in soil temperature between the beginning and the end of a given time period. From point view of soil thermal conductivity, Rycheva (1994) reported that podzolic soil thermal conductivity is lower during heating the soil than during its cooling, and is probably connected with thermal moisture transfer. His result was in similar trend reported by Campbell et al. (1994), who stated that soil thermal conductivity increased dramatically with temperature in moist soils. Their results proved that soil thermal conductivity could be specified as a function of bulk density, temperature and water content. Therefore, it could be concluded that, soil thermal conductivity may be considered as a property that controls heat flow through soil, consequently, affects heat fluctuation in soil. So, in the current study, soil thermal conductivity was one approach to be considered through thermal flux estimation. Therefore, different irrigation regimes were a factor involved in this study, and considered as management or control factor. The first law of heat conduction, known as Fourier's law, states that flux of heat in a homogeneous body is in the direction of, and proportional to the temperature gradient in one-dimensional form, this law is written as following (Hillel, 2004):

$$
q_{h}=-K_{x}(d T / d x) \quad \text { or } \quad q_{h}=-K_{z}(d T / d z)
$$

where $q_{h}$ is the thermal flux in $\mathrm{W} \mathrm{m} \mathrm{m}^{-2}$ or cal. $\mathrm{cm}^{-2}$ (i.e. the amount of heat conducted across a unit cross-sectional area in unit time), $K$ is thermal conductivity in $\mathrm{W} \mathrm{m} \mathrm{K}^{-1}$ or cal. $\mathrm{cm}^{-1} \mathrm{sec}^{-1}{ }^{\circ} \mathrm{C}^{-1}, d T / d x$ is the temperature gradient in any direction, designated $\mathrm{x}$, and $d T / d z$ is the gradient in the vertical direction representing soil depth $(z=0$ being the soil surface). This equation 
would be used to calculate the expected variation in heat flux (at the same time represented by the corresponding soil moisture content), to detect the magnitude of heat fluctuation among the different treatments as an important objective in this investigation. Generally, the present study was conducted to detect the optimum interaction between irrigation scheduling and soil warming, to have positive impact on plant environment.

\section{Material and Methods}

\section{Experiment layout}

A Field experiment was conducted in three unheated plastic greenhouses at Faculty of Agriculture, Suez-Canal Univ., Ismailia, Egypt. Each greenhouse was $3 \mathrm{~m}$ long, $2.5 \mathrm{~m}$ wide and $2.5 \mathrm{~m}$ height. Soil used was well drained, loamy sand and some physical and chemical properties are given in Table 1. Each greenhouse included two different soil treatments: the first one was mulched soil, where a black polyethylene sheet, $60 \mu \mathrm{m}$ in thickness, represented soil warming and the second was bare soil. Micro drip irrigation system was used to irrigate cucumber plant (Cucumis sativvs) transplanted in December, 2010. The irrigation system was used to achieve three different water regimes, namely: full soil field capacity in the first greenhouse; two third of soil field capacity in the second greenhouse, and one third of soil field capacity in the third. So, these soil moisture levels were interacted with both mulched and bare treatments (Fig. 1). The emitters used through the irrigation system were online self compensation, and according to laboratory testing, its average discharge rate was $4.26 \mathrm{~L} \mathrm{~h}^{-1}$ under working pressure ranged from 1.0 to 1.5 bar. Each greenhouse was irrigated separately to achieve its designed level of moisture regime. The amounts of applied water were quantified based on the difference between $5 \%$ and $15.5 \%$ soil moisture contents.

TABLE 1. Some physical and chemical properties of the experimental site $(0-30 \mathrm{~cm}$ depth)

\begin{tabular}{|l|c|}
\multicolumn{1}{|c|}{ Soil characteristics } & Values \\
\hline Texture & Loamy Sand \\
\hline Sand $(\%)$ & 86.3 \\
\hline Silt $(\%)$ & 5.6 \\
\hline Clay $(\%)$ & 8.1 \\
\hline Bulk density $\left(\mathrm{Mg} \mathrm{m}^{-3}\right)$ & 1.32 \\
\hline Organic matter $(\%)$ & 1.31 \\
\hline Soil field capacity $\left(\mathrm{g} \mathrm{g}^{-1} \%\right)$ & 15.5 \\
\hline EC $\left(\mathrm{dS} \mathrm{m}^{-1}\right)$ & 2.5 \\
\hline $\mathrm{pH}$ & 6.83 \\
\hline
\end{tabular}




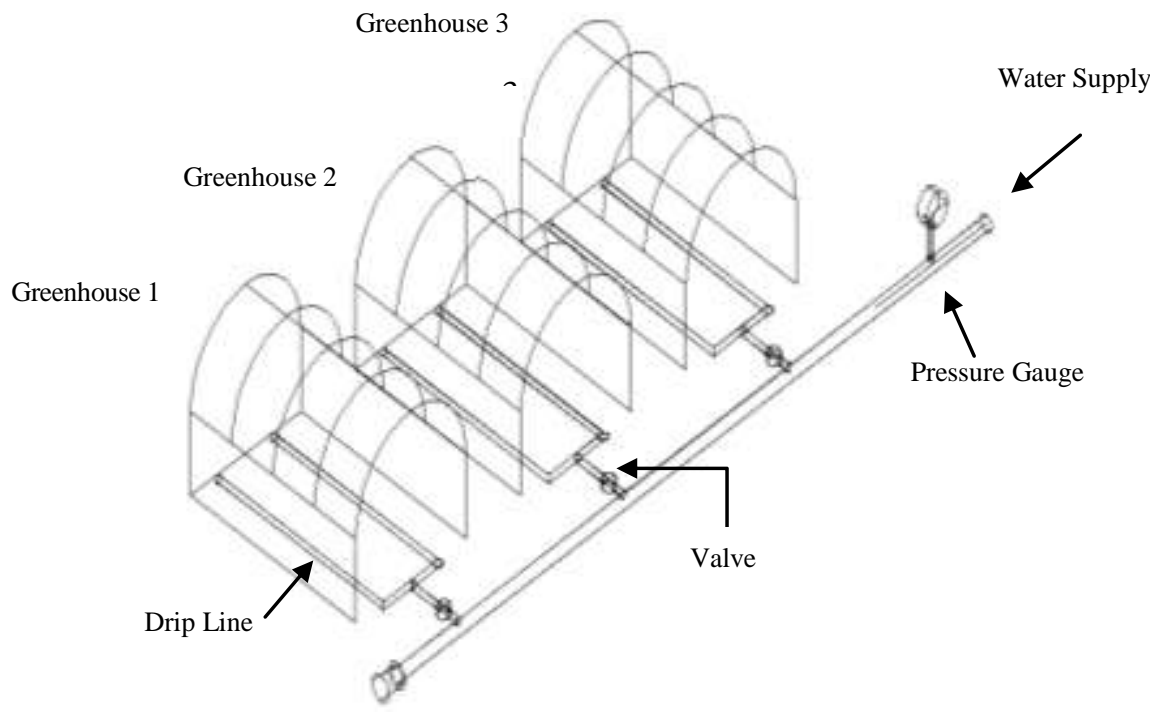

Fig. 1. Diagram of the experiment layout (three unheated plastic greenhouses)

Soil moisture and temperature measurements

To determine soil moisture content in three different soil depths (i.e., 10, 20 and $30 \mathrm{~cm}$ ) a micro soil auger was used for soil sampling. This measurement was achieved two days periodically under each soil treatment (i.e., both mulched and bare soil). Simultaneously, at the same three depths where soil moisture determined, soil temperatures were also two days periodically measured. Soil temperature values were recorded every two hours from 8:00 AM to 6:00 PM. To measure soil temperature, eighteen digital thermocouple-sensors (each one ended with wire's socket) were inserted permanently in soil next to the root zone at the three depths. For reading, a digital reader was connected to the sensor's wire and temperature values were recorded. At picking, plant height was measured from soil surface to the highest point of plant. Root depth (as a parameter strongly affected by soil temperature) and crop yield $\left(\mathrm{kg}\right.$ plant $\left.{ }^{-1}\right)$ were also recorded. These parameters were subjected to statistical analysis using "CoStat" program to detect the significant differences among the different treatments. Treatments of irrigation regimes were involved as main plot.

\section{Results}

\section{Soil moisture distribution}

For all treatments, applied water amounts were calculated based on soil moisture depletion theory, SMD, in which the initial water content along the 30 soil depth was in average $2.7 \%\left(\mathrm{~g} \mathrm{~g}^{-1}\right)$. Therefore, water applied on the 
transplanting day aimed to substitute $12.8 \%$ moisture content to bring the upper 10 $\mathrm{cm}$ soil layer to its field capacity, FC. Concerning that soil depth occupied by plant roots equaled $10 \mathrm{~cm}$, applied water amount was equivalent to $195 \mathrm{~m}^{3} \mathrm{ha}^{-1}$. On next days, soil moisture contents were determined two days periodically for the three soil depths (i.e., 10, 20 and $30 \mathrm{~cm}$ ), in which soil temperatures were measured every $2 \mathrm{hr}$ at the same day. The results indicated that not only the upper $10 \mathrm{~cm}$, but also, the whole $30 \mathrm{~cm}$ layer was closed to soil FC (i.e., 15.5\%) particularly under greenhouse 1, where moisture regime was brought back to $100 \% \mathrm{FC}$ compared to the other two treatments. Figures 2, 3 and 4 illustrated distribution of soil moisture contents under all treatments. Such figures showed that residual soil water contents were increased under mulched soils compared to the bare soil. In other words, evapotranspiration was higher under non-mulching treatments compared to that under mulched soils. Results showed also that, the highest moisture contents were stored at $20 \mathrm{~cm}$ depth rather than upper and lower depths.

Curves shown in Fig. 2 to 4 revealed that, there was clear fluctuation in moisture contents which may be normally owing to repeated irrigations. Generally, these fluctuations (represented by the deviation of each water content from the average value for the overall growing period) were greater under the bare soil treatments than the mulched soils. Values listed in Table 2 showed the average water content of the three soil layers, and summation of deviation, SD, for each moisture content from overall average, so, represented fluctuation of soil water content. Also, Table 2 included the values of crop yield, plant height and root depth as growth parameters, in addition to their statically analysis. The values of average water content indicated that difference between bare and mulched soils was increased from greenhouse no. 1 to greenhouse no. 3. Moreover, the lowest value of average water content, either for bare or mulched soil was found under greenhouse no. 3 , the highest fluctuation (the highest value of SD) was recorded under bare soil-greenhouse no. 1, while the lowest fluctuation was found under mulched soil in greenhouse no. 3. The results showed that values of crop yield were observationally varied. For all treatments, the changing trend of both plant height and root depth was the same, as well as, for crop yield.

Greenhouse no. 1, bare soil

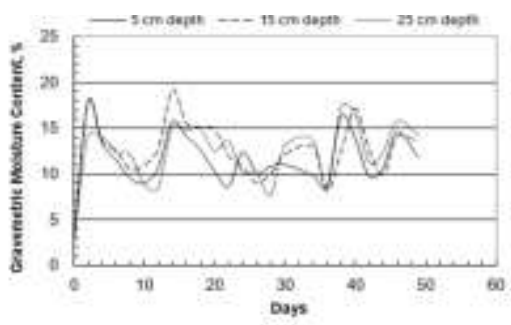

Greenhouse no. 1, mulched soil

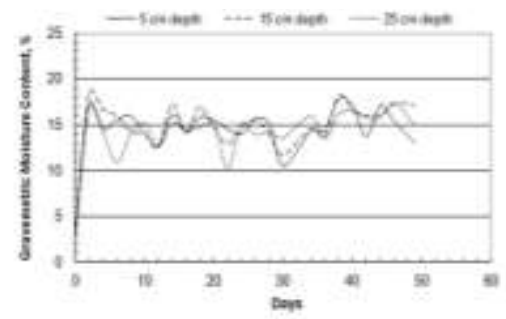

Fig. 2. Soil moisture fluctuations under greenhouse no. 1 at three soil depths, for both bare and mulched soils

Egypt. J. Soil. Sci. 56, No. 2 (2016) 
Greenhouse no. 2, bare soil

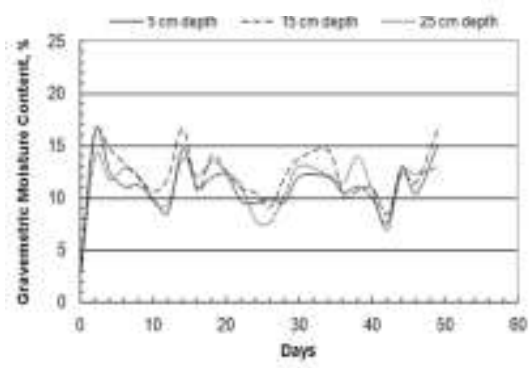

Greenhouse no. 2, mulched soil

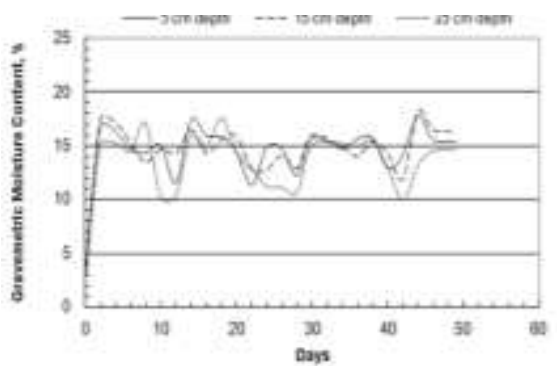

Fig. 3. Soil moisture fluctuations under greenhouse no. 2 at three soil depths, for both bare and mulched soils
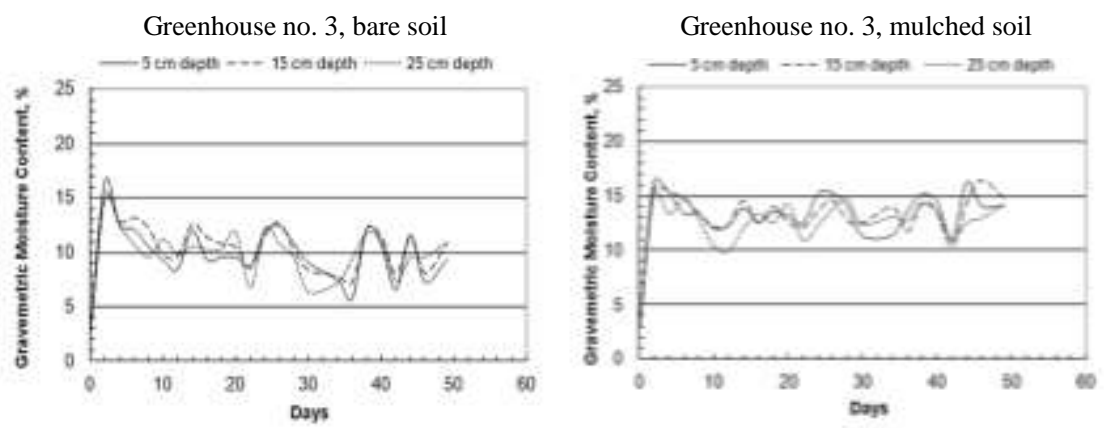

Fig. 4. Soil moisture fluctuations under greenhouse no. 3 at three soil depths, for both bare and mulched soils

TABLE 2. Average soil water content, $\% \mathrm{~g} \mathrm{~g}^{-1}$, summation of deviation, SD (represents fluctuation of water content around the average), crop yield, plant height and root depth

\begin{tabular}{|c|c|c|c|c|c|c|}
\hline \multirow[b]{2}{*}{ Paramet } & \multicolumn{2}{|c|}{ Greenhouse no. 1} & \multicolumn{2}{|c|}{ Greenhouse no. 2} & \multicolumn{2}{|c|}{ Greenhouse no. 3} \\
\hline & bare & Mulched & bare & mulched & bare & mulched \\
\hline Average soil water content & 12.4 & 15 & 11.7 & 14.6 & 10.4 & 13.4 \\
\hline SD & 45.7 & 25.2 & 36.3 & 30.1 & 34.7 & 22.8 \\
\hline Crop yield, kg plant ${ }^{-1}$ & 2.46 & 5.24 & 2.81 & 4.35 & 1.2 & 8.75 \\
\hline Plant height, $\mathrm{cm}$ & 135 & 170 & 137 & 185 & 87 & 182 \\
\hline Root depth, cm & 18 & 26 & 19 & 23 & 16 & 24 \\
\hline
\end{tabular}

SD values at 0.05 significance level:

\begin{tabular}{lccc}
\hline \multicolumn{1}{c}{ Factors } & Crop Yield & Plant Height & Root Depth \\
\hline Main Effect: Irrigation Treatments & 0.17 & 9.4 & 2.19 \\
Interaction Effect: Irrigation x Mulching & 0.26 & 16.01 & 4.51 \\
\hline
\end{tabular}

Egypt. J. Soil. Sci. 56, No. 2 (2016) 


\section{Soil temperature distribution}

Figures 5 to 7 illustrate the changes in soil temperature with time, occurred in each studied layer. Daily changes in soil temperature occurred overall the three different depths: 10, 20 and $30 \mathrm{~cm}$. Soil temperatures measured for all treatments at the same time of the day, at 6:00 PM. Figures showed a considerable variation in the maximum temperature to which the upper soil layer of $10 \mathrm{~cm}$ has been reached under different irrigation regimes. The maximum temperature under greenhouse no. (1) ranged in average from $23.2 \mathrm{C}^{\mathrm{o}}$ under mulching treatment to $21.1 \mathrm{C}^{\circ}$ in treatment without mulch, and the corresponding values ranged from 22.0 $\mathrm{C}^{\circ}$ to $21.5 \mathrm{C}^{\circ}$, and from $22.6 \mathrm{C}^{\circ}$ to $21.6 \mathrm{C}^{\circ}$ for greenhouses no. 2 and no. 3 , respectively. The figures also indicated that the highest changes in soil temperature (i.e. the highest fluctuations) occurred in the upper two layers, while the lowest fluctuation was observed in the deeper layer, $30 \mathrm{~cm}$, this finding agreed with that found by Campbell et al. (1994) and Zeng (2013). Generally, soil temperature recorded under mulched soils was higher than that under bare soils. All values showed that the highest temperature was recorded at the $10 \mathrm{~cm}$ upper layer followed by $20 \mathrm{~cm}$ then $30 \mathrm{~cm}$. Consequently, soil temperature fluctuations were observed at high degree in the upper layer then decreased as going lower.

\section{Heat storage and heat flux}

Great variation in soil temperature among the different treatments could be observed from Fig. 5 to 7 . Based on the change in soil temperature through the daytime (across a limited area and depth of soil), soil bulk density and its moisture content could be used to calculate soil heat storage as a static property using Eq. 1 (i.e. $\left.\mathrm{Q}_{\mathrm{q}}=\rho_{\mathrm{b}}\left(0.2+\theta_{\mathrm{m}}\right) \mathrm{V} \Delta \mathrm{T}\right)$. The variable $\mathrm{Q}_{\mathrm{q}}$ is the quantity of heat, in calories, flows in a defined volume of soil. This quantity which could flow across a unit area of soil section in $\mathrm{cm}^{2}$ along $10 \mathrm{~cm}$ soil depth to give 10 $\mathrm{cm}^{3}$ affected volume. $\mathrm{C}_{\mathrm{v}}$ is volumetric heat capacity of soil, and can be calculated by $\rho_{\mathrm{b}}\left(0.2+\theta_{\mathrm{m}}\right), \rho_{\mathrm{b}}$ is soil bulk density, equaled $1.32 \mathrm{~g} \mathrm{~cm}^{-3}$ for the studied soil, 0.2 was assumed to represent the specific heat in average of mineral soil, in cal. $\mathrm{g}^{-1} \mathrm{C}^{\mathrm{o}-1}$. The variable $\mathrm{V}$ is the affected soil volume in $\mathrm{cm}^{-3}$ and $\left(\mathrm{T}_{1}-\mathrm{T}_{2}\right)$ is the difference in soil temperature between the beginning and the end of $10 \mathrm{hr}$ period for each $10 \mathrm{~cm}$ soil layer, i.e. $\Delta \mathrm{T}$ in $\mathrm{C}^{0}$. Therefore, the equation became: $\mathrm{Q}_{\mathrm{q}}=$ $\left(0.264+\theta_{\mathrm{v}}\right) 10(\Delta \mathrm{T})$. Tables 3 and 4 included values of heat quantities stored in each $10 \mathrm{~cm}$ soil layer during a period of $10 \mathrm{hr}$ daily (from 8:00 AM to 6:00 PM) using Eq. 1. The results showed that different heat quantities stored in soils were posed by changes in soil temperature and its moisture regime. Generally, these heat quantities were increased as moisture content and soil temperature differences increased. 

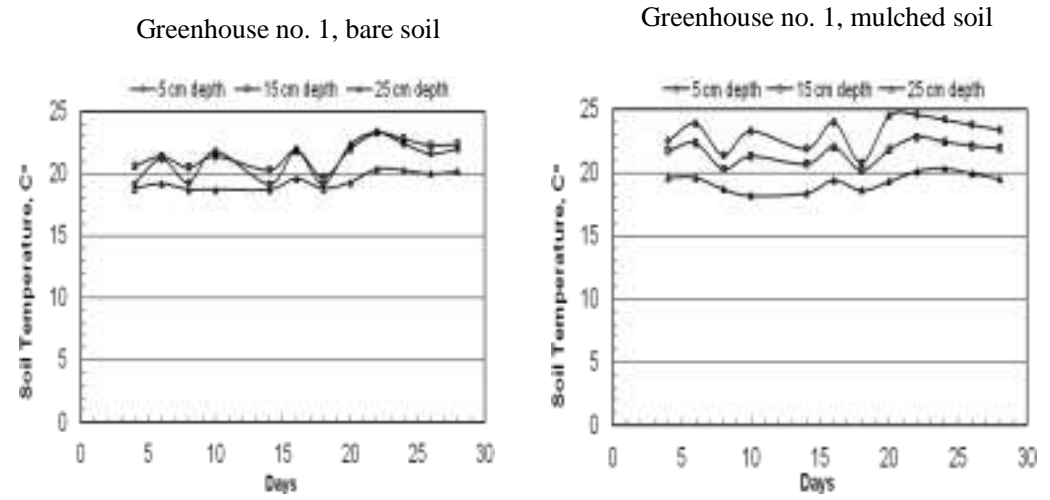

Fig. 5. Soil temperature fluctuations under greenhouse no. 1 at three soil depths
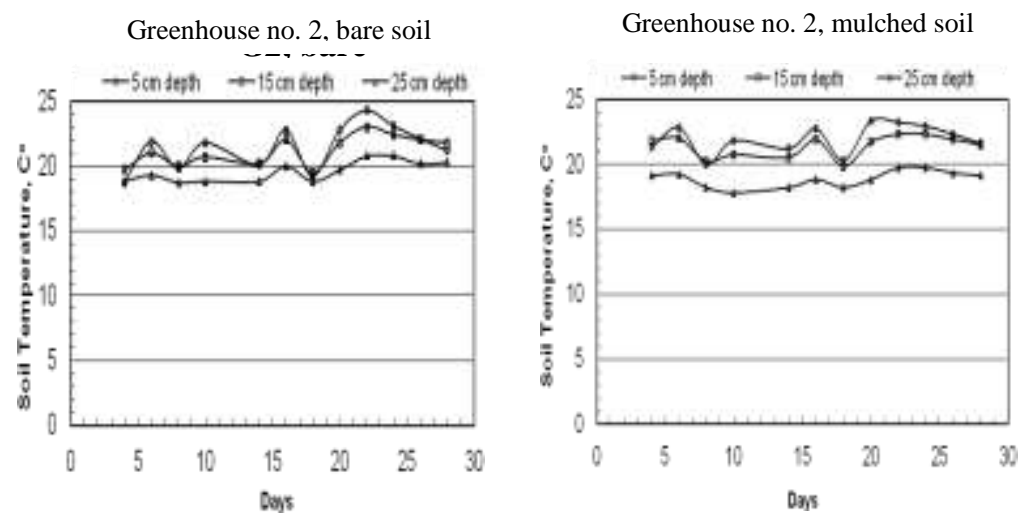

Fig. 6. Soil temperature fluctuations under greenhouse no. 2 at three soil depths
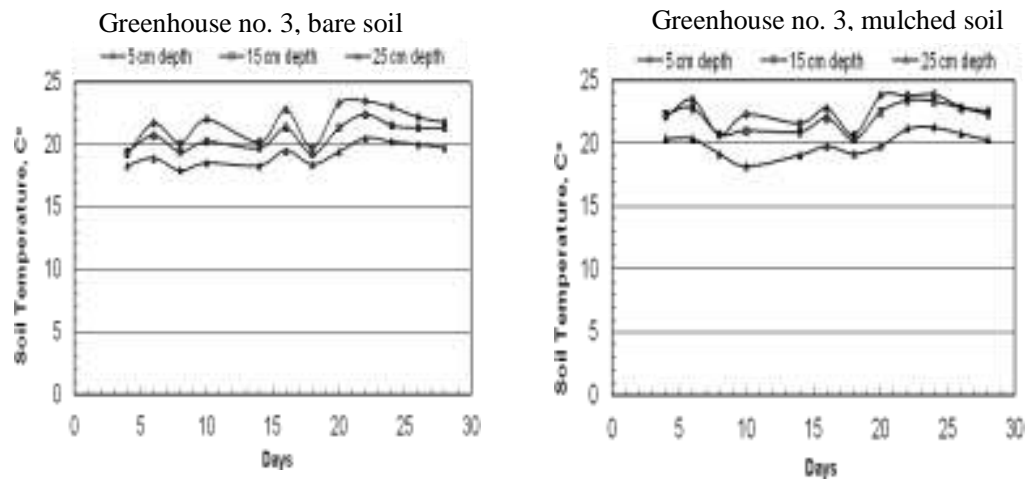

Fig. 7. Soil temperature fluctuations under greenhouse no. 3 at three soil depths

Egypt. J. Soil. Sci. 56, No. 2 (2016) 
TABLE 3. The quantity of heat, in calories, stored in $30 \mathrm{~cm}$ soil depth through 10 hours period, from 8:00 AM to 6:00 PM for bare soils under all treatments.

\begin{tabular}{|c|c|c|c|c|c|c|c|c|c|c|c|c|}
\hline \multirow{2}{*}{ Days } & \multicolumn{4}{|c|}{ Greenhouse no. 1} & \multicolumn{4}{|c|}{ Greenhouse no. 2} & \multicolumn{4}{|c|}{ Greenhouse no. 3} \\
\hline & $0-10 \mathrm{~cm}$ & $10-20 \mathrm{~cm}$ & $20-30 \mathrm{~cm}$ & sum & $0-10 \mathrm{~cm}$ & $10-20 \mathrm{~cm}$ & $20-30 \mathrm{~cm}$ & sum & $0-10 \mathrm{~cm}$ & $10-20 \mathrm{~cm}$ & $20-30 \mathrm{~cm}$ & sum \\
\hline 4 & 1347 & 1120 & 562.9 & 3030.4 & 1123 & 1199.5 & 485.6 & 2808.3 & 1163.6 & 1012.7 & 553.2 & 2729.5 \\
\hline 6 & 1423 & 1079 & 449.9 & 2951.9 & 1481 & 1250.5 & 552.4 & 3284.3 & 1489.1 & 1236.5 & 509.7 & 3235.3 \\
\hline 8 & 1059 & 906.5 & 422.9 & 2388.8 & 1311 & 1069.6 & 488 & 2868.2 & 1269.5 & 1047.3 & 414.8 & 2731.6 \\
\hline 10 & 1253 & 1152 & 367.8 & 2772.3 & 1336 & 1084.1 & 466.7 & 2887.2 & 1256.4 & 1000.5 & 391.4 & 2648.3 \\
\hline 14 & 1384 & 1372 & 564.6 & 3319 & 1416 & 1358.1 & 572.4 & 3346.3 & 1073.4 & 944.4 & 442.2 & 246 \\
\hline 16 & 1358 & 1419 & 672 & 3449 & 1152 & 1048.6 & 634.3 & 2834.5 & | 937.1 & 1022.7 & 540.7 & 2500.5 \\
\hline 18 & 590.2 & 524.3 & 239.6 & 1354.1 & 498 & 528.2 & 252.9 & 1279.1 & 414.8 & 393.2 & 181.5 & 989.5 \\
\hline 20 & 1276 & 1477 & 536.4 & 3289.2 & 1587 & 1290.8 & 603.5 & 3481.6 & 1257.5 & 1019.8 & 638.6 & 2915.9 \\
\hline 22 & 968.1 & 1253 & 694 & 2915.1 & 1215 & 1143.8 & 602.6 & 2961.4 & 866 & 769.8 & 352 & 1987.8 \\
\hline 24 & 983.2 & 830.1 & 344.1 & 2157.4 & $\mid$\begin{tabular}{||l}
842.4 \\
\end{tabular} & 821.5 & 306.4 & 1970.3 & 947.8 & 824.9 & 526.8 & 2299.5 \\
\hline 26 & 841 & 815 & 377 & 2033 & 948.8 & 834 & 324.4 & 2107.2 & 1072.9 & 1075 & 568 & 2715.9 \\
\hline 28 & 1034 & 969.4 & 359.2 & 2362.6 & $\mid 907.5$ & 1089.7 & 502.7 & 2499.9 & 982.5 & 922.2 & 505.6 & 2410.3 \\
\hline Average & & & & 2668.6 & & & & 2694 & & & & 2284.2 \\
\hline
\end{tabular}

TABLE 4. The quantity of heat, in calories, stored in $30 \mathrm{~cm}$ soil depth through 10 hours period, from 8:00 AM to 6:00 PM for mulched soils under all treatments.

\begin{tabular}{|c|c|c|c|c|c|c|c|c|c|c|c|c|}
\hline \multirow{2}{*}{ Days } & \multicolumn{4}{|c|}{ Greenhouse no. 1} & \multicolumn{4}{|c|}{ Greenhouse no. 2} & \multicolumn{4}{|c|}{ Greenhouse no. 3} \\
\hline & $0-10 \mathrm{~cm}$ & $10-20 \mathrm{~cm}$ & $20-30 \mathrm{~cm}$ & sum & $0-10 \mathrm{~cm}$ & $10-20 \mathrm{~cm}$ & $20-30 \mathrm{~cm}$ & sum & $0-10 \mathrm{~cm}$ & $10-20 \mathrm{~cm}$ & $20-30 \mathrm{~cm}$ & sum \\
\hline 4 & 1665 & 1358 & 594.1 & 3617.5 & 1611 & 1429.8 & 529.5 & 3569.8 & 1616.7 & 1275 & 536 & 3427.7 \\
\hline 6 & 2056 & 1389 & 395.9 & 3840.2 & 1702 & 1227.8 & 464.7 & 3394.6 & 1670.7 & 1324.2 & 513.9 & 3508.8 \\
\hline 8 & 1859 & 1016 & 427 & 3301.4 & 1418 & 916.2 & 411.6 & 2745.9 & 1383.2 & 1006 & 345.3 & 2734.5 \\
\hline 10 & 1943 & 1314 & 509.1 & 3765.6 & 1424 & 1199.5 & 289 & 2912.2 & 1477.9 & 1030.1 & 223.4 & 2731.4 \\
\hline 14 & 1660 & 1176 & 468.4 & 3305.1 & 1652 & 1103.2 & 446.5 & 3201.4 & 1355.2 & 1017.3 & 369.5 & 2742 \\
\hline 16 & 1547 & 948.2 & 520.1 & 3015.1 & 1531 & 1149.8 & 474.3 & 3155.1 & $\mid 1214.2$ & 989.1 & 467.1 & 2670.4 \\
\hline 18 & 740.7 & 589.3 & 170 & 1500 & 695.1 & 459 & 187.7 & 1341.8 & 657.5 & 487.9 & 150.9 & 1296.3 \\
\hline 20 & 2139 & 1278 & 584.8 & 4001.7 & 1792 & 1403.4 & 517.4 & 3712.4 & 1713.4 & 1163.6 & 517.4 & 3394.4 \\
\hline 22 & 1743 & 1001 & 357.9 & 3102 & 1092 & 995.5 & 466.1 & 2553.4 & 1257.3 & 1073.4 & 469.2 & 2799.9 \\
\hline 24 & 1295 & 943.9 & 448 & 2686.6 & 1127 & 841 & 301.3 & 2268.8 & 1344 & 1004.5 & 378.7 & 2727.2 \\
\hline 26 & 1656 & 1225 & 501.2 & 3382.5 & 1259 & 1056.4 & 314.2 & 2629.1 & $\mid 1371.1$ & 1193.4 & 498.5 & 3063 \\
\hline 28 & 1774 & 1182 & 479.1 & 3435.6 & 1080 & 1018.6 & 356.6 & 2455.2 & $\mid 1414.8$ & 1075 & 511.3 & 3001.1 \\
\hline Average & & & & 3246.1 & & & & 2828.0 & & & & 2841.4 \\
\hline
\end{tabular}

The listed data was based on the corresponding soil moisture content, $\theta \mathrm{v} \%$, and temperature difference, $\Delta \mathrm{T} \mathrm{C}^{\mathrm{o}}$.

Egypt. J. Soil. Sci. 56, No. 2 (2016) 
Eq. (2) that known as the first law of heat conduction (called Fourier's law) was used to introduce heat flux homogeneous body in the direction of, and proportional to, temperature gradient in onedimensional form (Hillel, 2004). Thermal conductivity (for such studied soil) involved in heat flux calculation was assumed to equal $2.612 * 10^{-3}$ cal. $\mathrm{cm}^{-1} \sec ^{-1}{ }^{\circ} \mathrm{C}^{-1}$, according to Abu-Hamdeh (2003). The quantity of $\mathrm{dT} / \mathrm{dx}$ represents temperature gradient in vertical direction and was calculated for the distance from the $5 \mathrm{~cm}$ point (in the middle of the first $10 \mathrm{~cm}$ layer) to 25 the $\mathrm{cm}$ point (in the middle of the deeper layer from $20-30 \mathrm{~cm}$ ). The difference in soil temperature, $\mathrm{dT}$, was that value between the same two points, i. e. 5 and $25 \mathrm{~cm}$ depths. Table 5 included soil heat flux values calculated using Eq. (2), where the obtained data could be considered as a function of heat fluctuation. Values of soil heat flux showed the expected variation among the different treatments and described the magnitude of heat transfer vertically through $20 \mathrm{~cm}$ soil depth.

TABLE 5. Soil heat flux, in cal. $\mathrm{cm}^{-1} \sec ^{-1}{ }^{\circ} \mathrm{C}^{-1}$, calculated by Eq. $2\left(q_{h}=-K_{x}(d T / d x)\right)$ for 5 to $25 \mathrm{~cm}$ soil depth, for 10 h period, from 8:00 AM to 6:00 PM for both mulched and bare soils

\begin{tabular}{c|ccc||c|ccc}
\hline \multirow{2}{*}{ Days } & \multicolumn{4}{|c||}{ Bare soil } & \multicolumn{4}{c}{ Mulched Soil } \\
& $\begin{array}{c}\text { Greenhouse } \\
\text { no. 1 }\end{array}$ & $\begin{array}{c}\text { Greenhouse } \\
\text { no. 2 }\end{array}$ & $\begin{array}{c}\text { Greenhouse } \\
\text { no. 3 }\end{array}$ & Greenhouse & Greenhouse \\
no. 1 & Greenhouse & no. 3 \\
\hline 4 & $5.22410^{-5}$ & $1.30610^{-5}$ & $1.17510^{-4}$ & $3.78710^{-4}$ & $2.87310^{-4}$ & $2.22010^{-4}$ \\
6 & $2.61210^{-4}$ & $3.39610^{-4}$ & $3.65710^{-4}$ & $5.61610^{-4}$ & $4.70210^{-4}$ & $4.04910^{-4}$ \\
8 & $7.83610^{-5}$ & $1.43710^{-4}$ & $2.87310^{-4}$ & $3.52610^{-4}$ & $2.35110^{-4}$ & $1.95910^{-4}$ \\
10 & $4.04910^{-4}$ & $3.91810^{-4}$ & $4.57110^{-4}$ & $6.66110^{-4}$ & $5.22410^{-4}$ & $5.35510^{-4}$ \\
14 & $6.53010^{-5}$ & $1.69810^{-4}$ & $2.48110^{-4}$ & $4.57110^{-4}$ & $3.91810^{-4}$ & $3.26510^{-4}$ \\
16 & $2.87310^{-4}$ & $3.65710^{-4}$ & $4.31010^{-4}$ & $6.00810^{-4}$ & $5.09310^{-4}$ & $3.91810^{-4}$ \\
18 & $5.22410^{-5}$ & $4.22410^{-5}$ & $1.69810^{-4}$ & $2.87310^{-4}$ & $2.74310^{-4}$ & $1.95910^{-4}$ \\
20 & $3.91810^{-4}$ & $4.04910^{-4}$ & $5.09310^{-4}$ & $6.79110^{-4}$ & $5.87710^{-4}$ & $5.22410^{-4}$ \\
22 & $3.78710^{-4}$ & $4.57110^{-4}$ & $3.91810^{-4}$ & $5.87710^{-4}$ & $4.57110^{-4}$ & $3.39610^{-4}$ \\
24 & $2.74310^{-4}$ & $3.00410^{-4}$ & $3.65710^{-4}$ & $5.09310^{-4}$ & $4.17910^{-4}$ & $3.39610^{-4}$ \\
26 & $2.09010^{-4}$ & $2.48110^{-4}$ & $2.87310^{-4}$ & $5.09310^{-4}$ & $3.91810^{-4}$ & $2.74310^{-4}$ \\
28 & $2.35110^{-4}$ & $1.17510^{-4}$ & $2.74310^{-4}$ & $5.09310^{-4}$ & $3.26510^{-4}$ & $3.00410^{-4}$ \\
\hline Average & $2.24210^{-4}$ & $2.50010^{-4}$ & $3.25010^{-4}$ & $5.08110^{-4}$ & $4.06010^{-4}$ & $3.37010^{-4}$ \\
\hline
\end{tabular}

\section{Discussion}

\section{Soil moisture distribution}

Although irrigation scheduling at the beginning of treatments was designed to bring only the upper $10 \mathrm{~cm}$ soil layer to its field capacity, the observed moisture content in whole $30 \mathrm{~cm}$ soil depth was closed to the soil FC. This finding may have resulted due to that, applied water amounts were calculated based on a 
limited area, while the water was actually applied to a specific point $(i . e$. under the emitter). Because of such finding, all three depths were closed to soil FC particularly under greenhouse no. 1. Therefore, during the whole growing season, soil depth involved in irrigation scheduling was constant and not increased. At the same time, soil moisture contents along all depths were periodically monitored and the irrigation process has been performed when soil moisture depleted and ranged between 5 - $68 \%$. Relationship represented in Fig. 2 to 4 between soil moisture content and days, indicated that residual soil water contents were increased under mulched soils compared to that under the bare. For example, at the $10^{\text {th }}$ day, the residual water content (as average of the three depths) reached 50\%, 33\% and 14\% under mulched soils greater than those of bare soils, for 1, 2 and 3 greenhouses, respectively. It is shown that, the highest moisture contents stored at $20 \mathrm{~cm}$ depth (compared to the upper and lower depths), thus it will have a positive impact on root growth and provide it with more available water. These results indicate that plastic mulch has an observed influence on water quantities stored in root zone, similar result was reported in many investigations (Richard, 1976 and Zhang et al., 2009).

Regarding to soil moisture fluctuations occurred under each treatment, soil moisture content and its deviation from the average indicated that there was a clear fluctuation in moisture contents, which appeared normally owing to repeated irrigation. Soil moisture fluctuation represented by summation of deviation, SD, from the average value of water content overall the growing period (Table 2) was greater under all bare soils than that under mulched. The results showed that the highest fluctuation was found under bare soil-greenhouse no. 1 , while the lowest fluctuation was recorded under greenhouse no. 3 mulched soil. Values of average water content indicated that difference between the bare soils and mulched soils were 2.6, 2.9 and 3\% for greenhouse no. 1, 2 and 3, respectively. Moreover, the highest water contents were recorded under all mulched soils (e. g. reached 15\% under greenhouse no. 1-mulched treatment), while the lowest values occurred under the bare, particularly greenhouse no. 3 bare soil. Generally, the lowest values of SD were found under all mulched soils than the bare and equaled 25.2, 30.1 and 22.8 for greenhouse no. 1, 2 and 3, respectively. On the other hand, there was great variations among the different treatments with regard to the observed values of crop yield, plant height and root depth. The statistical analysis showed significant differences in both main and interaction effects. Values of crop yield ranged from 1.2 to $8.75 \mathrm{~kg} \mathrm{plant}^{-1}$. Data in Table 2 indicated that, the highest three values (i. e. $4.35,5.24$ and $8.75 \mathrm{~kg}$ plant $^{-1}$ ) were found under the three mulched soils and closely affected by the values of SD through an inversely relationship. Therefore, in the next discussion, values of crop yield will be considered as a reference and base to decide the optimum interaction between soil water regime and temperature. It is noticeable from the data listed in Table 2 that, the changes in both plant height and root depth within the different treatments had the same trend, as well as, for crop yield. 
As Fig. 2-4 showed, there were clear fluctuations in soil moisture levels among the different treatments. Data in Table 2 showed that those fluctuations were arbitrary in treatments without mulching compared to mulched, appeared clearly in greenhouse no. 1 . However, it is clear that, there were some mulching treatments varied also in the degree of moisture content fluctuation. For example, this fluctuation was as little as possible in the treatment of greenhouse no. 3 (which has less moisture contents, and may resulted in a relative stress led to occurrence of slight fluctuation), followed by greenhouse no. 1 (with the highest irrigation regime), then greenhouse no. 2 (with the medium irrigation regime). Based on data listed in Table 2, it is likely that the degree of fluctuation in soil moisture content (regardless soil moisture content) has an influential role in the crop production. Although irrigation treatment in greenhouse no. 3 under which soil moisture content was reached one third of soil field capacity, the best results were recorded compared to greenhouses no. 1 and 2 which irrigated to full and two thirds soil FC, respectively. As evident from these results and based on data listed in Tables 3 and 4, it can minimize the fluctuation occurred in soil moisture contents, consequently minimizing heat fluctuations, by reducing water amounts added during the irrigation. Growth parameters, e. $g$. plant height, root depth and crop yield listed in Table 2 showed that the development of those parameters had responded in similar manner to water content fluctuation. Data of root depth, listed in Table 2 showed that increasing soil heat and moisture content under mulched treatments may lead to accelerate and encourage plant root growing and distribution, and probably was the most important process for nutrients uptake. Similar results were reported by Ahn et al. (1999) and Gregory (2006). On the other hand, data showed that all bare soil treatments revealed high moisture fluctuations; therefore, this may be associated with its low yield production. Also, data showed that low moisture contents in bare soil such as greenhouse no. 3 may associate with high soil temperature, consequently increased evaporation from soil and contributed to dried soil. Moisture contents determined at the different depths of bare soils showed that, except for the full field capacity treatment, moisture content was graded from $30 \mathrm{~cm}$ to $10 \mathrm{~cm}$ depth. Therefore, according to Saito et al. (2006) and Zeng (2013), using values of soil moisture and temperature gradient, the HYDRUISD-ID code may be applied for such well-drained soil to observe the changes in soil water content due to the movement of liquid water, vapor and heat. They reported that, the simulated values of soil temperature and water content were in good agreement with the measured values. There was somewhat similarity between the conditions of the current study and that of Zeng (2013), as following:

\begin{tabular}{cccccc} 
& Soil used & $\begin{array}{c}\text { Average T } \\
\text { ambient, } \mathbf{C}^{\mathbf{0}}\end{array}$ & $\begin{array}{c}\text { Relative } \\
\text { humidity, } \\
\mathbf{\%}\end{array}$ & $\begin{array}{c}\Delta \mathbf{T} \text { between } \\
\mathbf{1 0}-\mathbf{3 0} \mathbf{~ c m} \\
\mathbf{d e p t h}\end{array}$ & $\begin{array}{c}\text { Wind } \\
\text { speed, } \mathbf{m} \\
\mathbf{s e c}^{-\mathbf{1}}\end{array}$ \\
\hline $\begin{array}{c}\text { Current } \\
\text { study }\end{array}$ & $\begin{array}{c}\text { Well-drained } \\
\text { loamy sand }\end{array}$ & 29.0 & 40 & 2.0 & 0 \\
Zeng's study & $\begin{array}{c}\text { Well-drained } \\
\text { sand }\end{array}$ & 31.7 & 34 & 1.8 & $0-1.5$
\end{tabular}




\section{Soil temperature distribution}

Many investigators such as Hummel et al. (2002) indicated that type of ground cover significantly affected temperature in upper $12 \mathrm{~cm}$ of the soil. Results of the current study showed that changes in soil temperature occurred in each studied layer, particularly, in 0-10 and 10-20 cm soil layers (Fig. 5-7 and Tables $3 \& 4$ ). The daily changes in soil temperature occurred overall the three different depths. Figures 5-7 showed a considerable variation in the maximum temperature to which the upper soil layer of $10 \mathrm{~cm}$ has been reached under different water regimes. The maximum soil temperature ranged in average from $23.5 \mathrm{C}^{0}$ (mulched soil) to $21.1 \mathrm{C}^{\circ}$ (bare soil), from $22.1 \mathrm{C}^{\mathrm{o}}$ to $21.5 \mathrm{C}^{\mathrm{o}}$, and from $22.8 \mathrm{C}^{\mathrm{o}}$ to $21.6 \mathrm{C}^{\mathrm{o}}$ for greenhouse no. 1,2 and 3 , respectively. Increasing soil temperature under greenhouse no. 1 compared to other treatments may be attributed to the interaction between the mulching with black plastic and at the same time increasing soil heat capacity due to its high moisture content. Obtained results showed that soil temperature at $30 \mathrm{~cm}$ depth began to be damped, and this agreed with that found by Zeng (2013). Also, similar findings were found by Campbell et al. (1994), who stated that, damping depths would therefore be expected to be about the mean temperature for the period of oscillation because temperature fluctuations would be only $5-10 \%$ of temperature fluctuation at the surface. However, results also indicated that the highest changes in soil temperature (i.e. the highest fluctuations) occurred in the upper two layers, while the lowest fluctuation was observed in the deeper layer (i.e. from 20 to $30 \mathrm{~cm}$ depth). In general, and as average of the three layers, soil temperature in mulched soil increased in few degrees compared to that of bare soil, where the temperature difference did not exceed 0.8 and $1.1 \mathrm{C}^{\mathrm{o}}$ for no. 1 and 3 greenhouses, respectively. So, the black polyethylene sheet does not play a major role in soil heating. Similar results were reported by Hopen (1964); Haddadine (1982) and El-Nemr (2006) who reported that, the major role was represented in evapotranspiration reduction as shown in Fig. 2 - 5. This may be owing to that mulching prevents cooling of soil surface due to evaporation, therefore, reducing outgoing radiation and evaporation, thus resulted in few increasing soil temperature. Although, soil temperature fluctuations were observed at high degree in the upper layer then decreased towards beneath (Fig. 5-7), increasing in soil temperature under mulching treatment in greenhouse no. 1 was higher than that recorded under mulched soils in greenhouse no. 2 and 3. So, usage of such black covering sheet may reduce soil heat fluctuation, particularly, with low moisture content.

\section{Heat storage and heat flux}

Generally, under all treatments the deeper the studied soil layer decreased the amount of heat stored, particularly, for mulched treatments, (Tables 2 and 3). In other words, the highest heat storage was found in upper layers. Mulching could prevent cooling of the soil surface due to evaporation reduction, and at the same time absorbs most of radiation and becomes greatly warmed, consequently, some energy passed to warm the soil. Therefore, and based on that the soil moisture content is one of the major factors which influence heat storage in soil, it is expected that a great heat will be stored in soil during daylight, with a limitation Egypt. J. Soil. Sci. 56, No. 2 (2016) 
of cooling during the nighttime, so, resulted in heat gain during the growing period of plant. Generally, results recorded in Tables 3 and 4 indicated that the quantities of heat stored in the deeper layer (i.e., $20-30 \mathrm{~cm}$ depth) were almost the lowest quantity either for bare or mulched soils. Comparing the amount of heat stored under all moisture regimes, with their average value listed in Table 2, it was found that the dominant trend was increasing the amount of heat stored with increasing average soil moisture content. There was an observed difference in amounts of heat storage happened between greenhouses no. 1 and no. 2 under mulched soil. Amount of heat increased from 2828.0 cal. in greenhouse no. 2 to 3246.6 in greenhouse no. 1 (i.e., increasing about $14.8 \%$ ), despite the increasing in moisture content was about $2.7 \%$ (i. e., in average from 14.6 to $15 \%$ for no. 2 and 1 greenhouses, respectively). Also, the increase in temperature was about $3.4 \%$ (i.e., in average from 20.7 to $21.4 \mathrm{C}^{\mathrm{o}}$ for 2 and 1 greenhouse, respectively). Therefore, a slight increasing in both soil moisture and temperature will result in a magnitude increasing in heat storage. On the other hand, amount of heat stored in greenhouse no. 3 mulched soil (equals to 2841.4 cal.) had a value close to that of greenhouse no. 2 mulched treatment despite that average soil temperature increased observably than that for greenhouse no. 2 mulched soil, and the moisture content decreased to $13.4 \%$. From above mentioned, it could be concluded that heat quantity stored in soil was sharp and more influenced by changing in soil temperature compared to the changing in soil moisture content, particularly, that temperature difference involved in estimation of heat storage. Therefore, values of soil heat storage haven't the same trend with changing of crop yield, root depth and plant height as showed for soil moisture contents and its $\mathrm{SD}$ values.

Based on the above mentioned, mulched soil will be warmed up slowly, because of the great storage of heat during the day-time, and consequently provide a suitable heat exchanger or a limitation of cooling during the night-time. Comparison between summation deviations of soil moisture contents and values of heat storage as a static property showed that there was no symmetric trend. According to Eq. 2, soil thermal conductivity (as a major factor affecting heat flux process) appeared to be associated with thermal moisture transfer. Campbell et al. (1994) reported that soil thermal conductivity increased dramatically with temperature in moist soils. Therefore, using Eq. 2 soil thermal conductivity could be considered as function of bulk density, temperature and water content, consequently, may be considered as a dynamic property that controls heat flow and affects heat fluctuation in soil. Soil heat flux was calculated to detect the expected variation among the different treatments (at the same time represented by corresponding soil moisture content with which heat storage has been calculated). Soil heat flux describes the magnitude of heat transfer vertically through $20 \mathrm{~cm}$ soil depth, consequently, the obtained values may be used as a function of heat fluctuation. Data in Table 5 showed that soil heat flux was increased under mulched soil treatments than that under bare soil, particularly for greenhouses no. 1 and 2. Either for mulched or bare soils there was a great variation among the heat flux values under different irrigation treatments. Soil heat flux decreased as irrigation water regimes decreased, and it reached in 
average 5.081 $10^{-4}, 4.06010^{-4}$ and $3.337010^{-4} \mathrm{cal}^{\mathrm{cm}} \mathrm{cm}^{-1} \mathrm{sec}^{-1}{ }^{\circ} \mathrm{C}^{-1}$ for no. 1,2 and 3 greenhouses mulched soils, respectively. Table 5 also showed that, both bare and mulched soils in greenhouse no. 3 have approximately the same value of heat flux. On the other hand, the data showed a great difference between the both greenhouse no. 3 treatments regarding to crop yield and SD. This finding means that the interaction between soil heat flux and SD must be considered as an important criterion for good plant growth. In other words, although mulched soils in greenhouses no. 2 and 3 have close values of soil water content, both treatments have about $20 \%$ different in heat flux values. Such difference may be attributed to a similar variation $\Delta \mathrm{T}$ involved in heat flux estimation. Compared to heat storage values, data of crop yield, summation of deviation and heat flux indicated that, under mulched soil both summation of deviation and heat flux are the parameters which can guide to predict the crop yield. Moreover, decreasing both summation of deviation and soil heat flux may be the recommended interaction for suitable plant growth.

\section{Soil temperature fluctuations and yield production}

According to the thermal inertia concept, Lakshmi et al. (2003) reported that wetted soil will exhibit smaller surface temperature amplitude due to the thermal inertia of the water in soil. Curves of soil moisture fluctuation and temperature fluctuation under the different soil moisture regimes indicated the lowest fluctuation in soil moisture under greenhouse no. 3 compared to other greenhouses may have resulted in reducing the fluctuations of soil temperature (represented by heat flux as shown in Table 5). This result agreed with Fan and Liu (2003), they reported that, when initial soil water content increased, soil temperature (through $40 \mathrm{~cm}$ soil depth) will change more intensively and rapidly than those when initial water content is low. As shown in Fig. 5-7, this behavior has appeared in the upper two layers, and is likely that it may play a significant role in increasing the vegetative growth of crop. On other hand, Ahn et al. (1999) reported that roots of cucumber plants suffered seriously at temperature below $20 \mathrm{C}^{\circ}$. Also, Gregory (2006) found that the optimum temperature (depend upon plant species) are typically in the range of $25-35 \mathrm{C}^{\circ}$. Therefore, the relative high crop yield obtained and growth parameters recorded under mulched soil of full FC and two third irrigation regimes may be attributed to the high temperature. Under such both treatments, average soil temperature in the more effective zone for root depth $\left(i . e\right.$., the uppermost $20 \mathrm{~cm}$ ) were 22.7 and $22.5 \mathrm{C}^{\circ}$, compared to $21.6 \mathrm{C}^{\mathrm{o}}$ in greenhouse no. 3. Also, Table 2 indicated that increasing values of the plant parameters and crop yield may be associated with the increasing in soil moisture content caused by losses of evaporation of soil water and increasing the heat quantities stored in soil under mulching treatment, compared to bare soils. The data showed that mulched soil in greenhouse no. 3 with $13.4 \%$ average moisture content and 3841.4 cal. of heat storage, had the highest value of crop yield, $8.75 \mathrm{~kg} \mathrm{plant}^{-1}$. On the other hand, bare soil in greenhouse no. 3 with $10.4 \%$ average moisture content and 2284.2 cal. heat storage had the lowest crop yield, $1.2 \mathrm{~kg} \mathrm{plant}^{-1}$. Similar results were reported by Gajri et al. (1994), Jain et al. (2000), Khurshid et al. (2006) and Seyfi \& Rashidi (2007).

Egypt. J. Soil. Sci. 56, No. 2 (2016) 


\section{Conclusion}

Generally, soil temperature at different soil depth was changed periodically with the periodical changes in soil moisture regimes. During the most parts of the day, soil moisture and temperature in the uppermost $20 \mathrm{~cm}$ layers were higher than those in the deeper layer, which leads to a greater increase of soil heat storage. Black plastic sheet resulted in a slight increase in soil temperature, where the difference between bare and mulched soils not exceeds $1.1 \mathrm{C}^{\mathrm{o}}$. On the other hand, this covering may reduce soil heat fluctuation and reduce soil water evaporation. Compared to heat storage values, both summation deviation of moisture contents and heat flux were parameters which could guide to predict the crop yield and plant growth. Moreover, decreasing both soil moisture fluctuations and soil heat flux interacted with high moisture content may be the recommended practice for suitable plant growth condition, additionally, irrigation hours could be reduced. So, this result has a significant practical importance, where the irrigation process can be achieved using a limited water source. The modified HYDRUSID-ID code for deep understanding of coupled water, vapor and heat transfer may be helpful here to quantitative study of moisture transport in soil under field conditions. The average soil temperature in the active root zone (the uppermost $20 \mathrm{~cm}$ ) was more suitable for high plant growth and crop yield under mulched soil of full FC and two third irrigation regimes compared to the other treatments.

Acknowledgment: The instrumentation and financial support provided by Department of Agricultural Engineering, Faculty of Agriculture, Suez-Canal University is gratefully acknowledged. Thanks are also extended to Dr. Rashaad (Assis. Prof. of Agric. Engi.) for his assistance and technical help.

\section{References}

Abu-Hamdeh, N.H. (2003) Thermal properties of soils as affected by density and water content. Biosystem Engineering, 86(1), 97-102.

Ahn, S.J., Im, Y.J., Chung, G.C., Cho, B.H. and Suh, S.R. (1999) Physiological responses of grafted-cucumber leaves and rootstock roots affected by low root temperature. Scientia Horticulture. Vol. 81, 397-408.

Arin, L. and Ankara, S. (2001) Effect of low-tunnel, mulch and pruning on the yield and earliness of tomato in unheated glasshouse. J. Appl. Hort., 3 (1), 23-27.

Barlow, E.R., Sepaskhah, A.R. and Boersma, L. (1974) Subsurface heating and irrigation of soils: Its effect on temperature and water content and on plant growth. Project Completion Report. Soil Science Dept., Water Resources Research Institute, Oregon State University.

Boersma, L. (1972) Growth response of corn to changes in root temperature and soil water suction measured with an LVDT. J. of Crop Sci. 12, 251-252. 
Buol, S.W., Sanchez, P.A., Weed, S.B. and Kimble, J.M. (1990) Predicted impact of climatic warming on soil properties and use. In: Kimball BA, Rosenberg NJ, Jones LH., "Impact of Carbon Dioxide, Trace Gases and Climate Change on Global Agriculture" Amer. Soc. Agron. Special Publication No. 53, Madison, WI.

Campbell, G.S., Jungbauer, J.D., Bidlake, W.R. and Hungerford, R.D. (1994) Predicting the effect of temperature on soil thermal conductivity. Soil Science, 158 (5), 307-313.

El-Nemr, A.M. (2006) Effect of mulch types on soil environmental conditions and their effect on the growth and yield of cucumber plants. Journal of App. Sci. Res. 2(2), 67-73.

Fan, A.W. and Liu, W. (2003) Simulation of the daily change of soil temperature under different conditions. Heat transfer-Asian Research, 32 (6), 533-544.

Farias-Larios, J., Orozco, M., Guzman, S. and Aguilar, S. (1994) Soil temperature and moisture under different plastic mulches and their relation to growth and cucumber yield in a tropical region. Gartenbauwissenschaft., 59(6), 249-252.

Gajri, P.R., Arora, V.K. and Chaud, M.R. (1994) Maize growth, response to deep tillage, straw mulching and farmyard manure in coarse soils of N. W. India. Soil Use Manag., 10, 15-20.

Gregory, P.J. (2006) Plant Roots: Growth, Activity and Interaction with Soils. Blackwell publishing Ltd, Oxford, UK. pp 132.

Haddadine, S.H. (1982) Effect of plastic mulches on soil water conservation, soil temperature, and yield of Tomato in the Jordan Valley. 168pp. MSc. Thesis, University of Jordan.

Hanks, R.J. and Ashcroft, G.L. (1980) Applied Soil Physics: Soil Water. (Editors: Bommer, D. Rome; Sabey, B. Fort Collins; Thomas, G. Lexington; Vaadia, Y. BetDagan; and van Vleck, L. Ithaca). Springer-Verlag: Berlin, Heidelberg, New York.

Hassanain, A.A. and Hokam, E.M. (2005) Trombe-Wall storage effect on the greenhouse passive solar heating. Egypt. J. of Appl. Sci., 20 (8B), 710-740.

Hillel, D., Warrick, A.W., Baker, R.S. and Rozenzweig, C. (1998) Environmental Soil Physics. Academic Press: San Diegon, London, Boston, New York, Sydney, Tokyo and Toronto.

Hillel, D. (2004) Introduction to Environmental Soil Physics. Acad. Press, El-Sevier Sci. USA.

Hopen, H.J. (1964) Effect of black and transparent polyethylene mulches on soil temperature, sweet corn growth and maturity in cool season. Proc. Amer. Soc. Hort., Sci., 89, 415-420.

Hummel, R.L., Walgenbach, J.F., Barbercheck, G.G., Kennedy, G.D., Hoyt, G.D. and Arellano, C. (2002) Effect of production practices on soil-borne 
entomopathogens in Western North Carolina vegetable systems. Environmental Entomology, 31 (1), 84-91.

Khurshid, K., Iqbal, M., Arif, M.S. and Nawaz, A. (2006) Effect of tillage and mulch on soil physical properties and growth of maize. Int. J. Agric.Biol., 5, 593-6.

Jain, N., Chauhan, H.S., Singh, P.K. and Shukla, K.N. (2000) Response of tomato under drip irrigation and plastic mulching In: Proceeding of 6th International Microirrigation Congress, Micro-irrigation Technology for Developing Agriculture. 22-27 October 2000 South Africa.

Lakshmi, V., Jackson, J. and Zehrfuhs, D. (2003) Soil moisture-temperature relationships: results from two experiments. J. of Hydrological Processes. 17, 30413057.

Milly, P.D. (1984) A simulation analysis of thermal effects on evaporation from soil. Water Resources Res. 20(8), 1087-1098.

Pahlavanian, A.M. and Silk, W.K. (1988) The effect of temperature on spatial and temporal aspects of growth in the primary maize root. Plant Physiol. 87, 529-532.

Richard, P. (1976) Plastic mulching for vegetable production. Grower guide Book, 7, 40.

Rycheva, T.A. (1994) Thermal conductivity of sod-podzolic soil: Effect of moisture movement. Eurasian Soil Science, 26 (6), 82 - 87.

Saito, H., Simunek, J. and Mohanty,B.P. (2006) Numerical analysis of coupled water, vapor, and heat transport in the vadose zone. Vadose Zone J. 5(2), 784-800.

Salman, S.R., Abou-Hadid, A.F. and El-Beltagy, M.S. (1992) Plastic house microclimate as affected by low tunnels and plastic mulch. Egyptian Journal of Horticulture. publ., 1993, 19(2), 111-119.

Salzmann, W., Bohne, K. and Schmidt, M. (2000) Numerical experiments to simulate vertical vapor and liquid water transport in unsaturated non-rigid porous media. Geoderma, 98(3), 127-155.

Sanders, D.G. (2001) Using plastic mulches and drip irrigation for vegetable production. Report from Horticulutral Sci. Dept. Published by U. S. Dept. of Agriculture, North Carolina Uni.

Scanlon, B.R. and Milly, PCD (1994) Water and heat fluxes in desert soils 2. Numerical simulations. Water Resources Res. 30(3),721-734.

Seyfi, K. and Rashid, M. (2007) Effect of Drip Irrigation and Plastic Mulch on Crop Yield and Yield Components of Cantaloupe. International Journal of Agriculture \& Biology, 247-249.

Weber, C (2000) Biodegradable foil mulch for pickling cucumber crop. Zeitschrift von Gemuse Muenchen, 36(4), 30-32. 
Wien, H.C. and Minotti, P.L. (1987) Growth, yield and nutrient uptake of fresh-market tomatoes as affected by plastic mulch and initial nitrogen rate. J. Amer. Soc. Sci. 112 (5), 759-763.

Yang, F.K., Wang, L.M. and Zhang, G.H. (2013) Effects of plastic film mulching with double ridges and furrow planting on soil moisture and temperature and soybean yield on a semiarid dryland of Gansu Province, N. W. China. J. of Ying Yong Sheng Tai Xue Bao. 24 (11), p. 3145.

Zhang, Y., Chen, W., Smith,S.L., Riseborough, D.W. and Cihlar, J. (2005) Soil temperature in Canada during the twentieth century: Complex responses to atmospheric climate change. J. Geophys. Res., 110, D03112, doi: 10.1029L2004JD004910.

Hang, Q.T., Ahmed, O.A., Inoue, M., Saxena, M.C., Inosako, K. and Kondo, K. (2009) Effects of mulching on evapotranspiration, yield and WUE of Swiss chard (Beta vulgaris L. var. flavescent) irrigated with diluted seawater. J. of Food, Agric. \& Environ. 7 (3\&4): 650-654.

Zeng y. (2013) Diurnal Pattern of Coupled Moisture and Heat Transport Process. Coupled Dynamics in Soil. Springer Theses 2013, 17-40.

(Received 4/5/2015;

accepted 30/5/2015) 
OPTIMUM INTERACTION BETWEEN SOIL WATER REGIME AND SOIL WARMING 229

$$
\text { ملائمة لنمو الأمثل بين النظام المائي بالثربة وتدفئتها من أجل ظروف }
$$

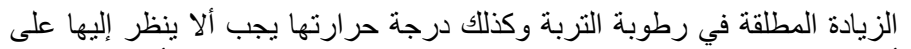

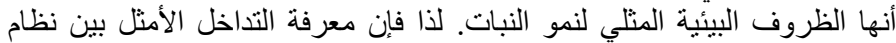

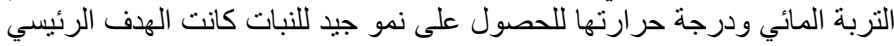

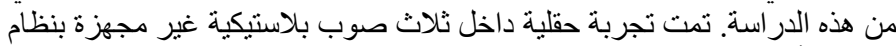

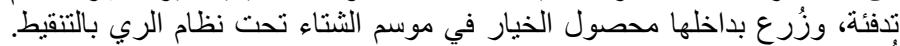

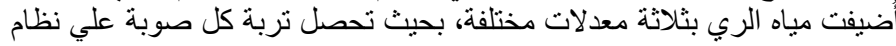

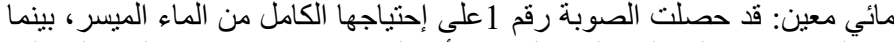

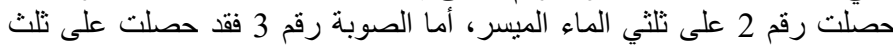

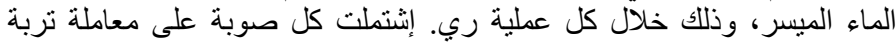

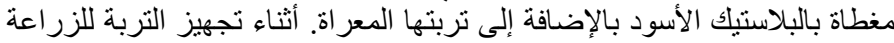

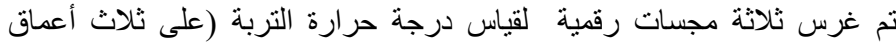

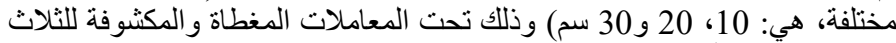

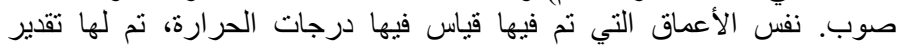

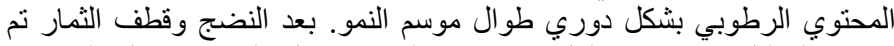

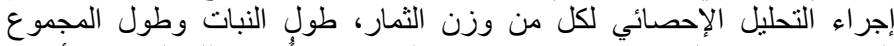

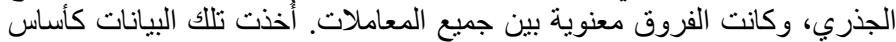

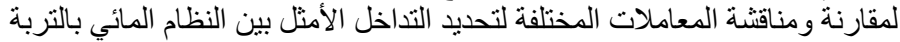

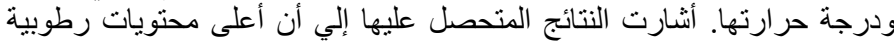

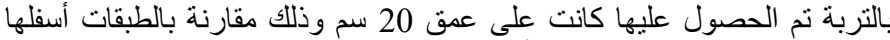

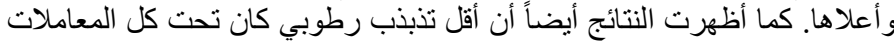

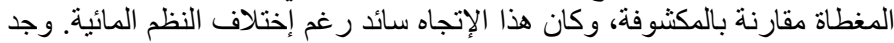

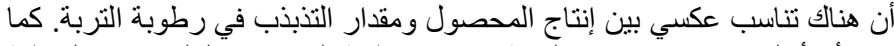

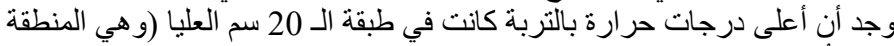

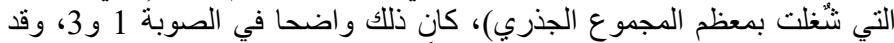

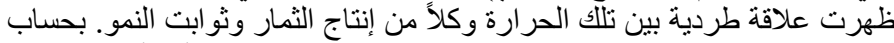

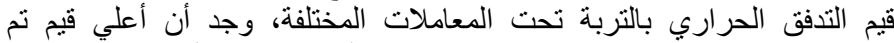

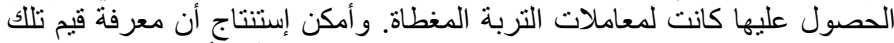

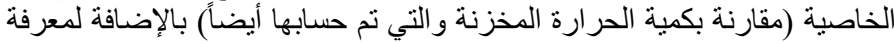

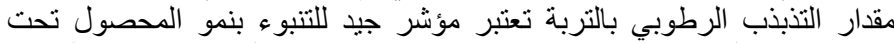

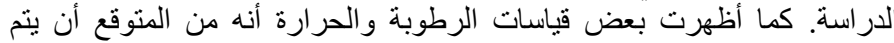

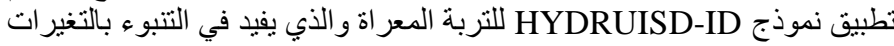
اليومية المتوقعة في ديناميكية الماء بالتربة. 